\title{
Metazoan stress granule assembly is mediated by P-elF2 $\alpha$-dependent and -independent mechanisms
}

\author{
NATALIE G. FARNY, ${ }^{1}$ NANCY L. KEDERSHA, ${ }^{2}$ and PAMELA A. SILVER ${ }^{1}$ \\ ${ }^{1}$ Department of Systems Biology, Harvard Medical School, Boston, Massachusetts 02115, USA \\ ${ }^{2}$ Department of Rheumatology, Immunology and Allergy, Brigham and Women's Hospital, Boston, Massachusetts 02115, USA
}

\begin{abstract}
Stress granules (SGs) are cytoplasmic bodies wherein translationally silenced mRNAs are recruited for triage in response to environmental stress. We report that Drosophila cells form SGs in response to arsenite and heat shock. Drosophila SGs, like mammalian SGs, are distinct from but adjacent to processing bodies (PBs, sites of mRNA silencing and decay), require polysome disassembly, and are in dynamic equilibrium with polysomes. We further examine the role of the two Drosophila elF2 $\alpha$ kinases, PEK and GCN2, in regulating SG formation in response to heat and arsenite stress. While arsenite-induced SGs are dependent upon eIF2 $\alpha$ phosphorylation, primarily via PEK, heat-induced SGs are phospho-eIF2 $\alpha$-independent. In contrast, heat-induced SGs require elF $2 \alpha$ phosphorylation in mammalian cells, as non-phosphorylatable elF2 $\alpha$ Ser51Ala mutant murine embryonic fibroblasts do not form SGs even after severe heat shock. These results suggest that mammals evolved alternative mechanisms for dealing with thermal stress.
\end{abstract}

Keywords: stress granules; Drosophila; eIF2 $\alpha$; arsenite; heat shock

\section{INTRODUCTION}

The importance of RNA localization to subcellular bodies in many biological processes has become increasingly apparent. Various types of localized RNA bodies, known as RNA granules, are involved in functions as diverse as local translational control in neurons, regulation of maternal effect genes in developing embryos, and mRNA decay in many eukaryotic organisms (for reviews, see Anderson and Kedersha 2006; Kiebler and Bassell 2006; Eulalio et al. 2007; Anderson and Kedersha 2008). While many types of RNA granules are constitutively present, stress granules (SGs) are formed specifically in response to environmental stress. Stress stimuli such as heat shock or oxidative stress inhibit translation of most cellular mRNAs. When general translation initiation is thus inhibited, actively translating polysomes become disassembled. The mRNAs and associated

Abbreviations: SG, stress granule; PB, processing body; GFP, green fluorescent protein; eIF, eukaryotic initiation factor; PEK/PERK, pancreatic eIF2 $\alpha$ kinase/PKR-like ER-localized eIF2 $\alpha$ kinase; GCN2, general control nonderepressing 2 kinase; MEF, mouse embryonic fibroblast.

Reprint requests to: Pamela A. Silver, Department of Systems Biology, Harvard Medical School, 200 Longwood Avenue, Boston, MA 02115, USA; e-mail: pamela_silver@hms.harvard.edu; fax: (617) 432-5012.

Article published online ahead of print. Article and publication date are at http://www.rnajournal.org/cgi/doi/10.1261/rna.1684009. initiation factors and RNA binding proteins from these disassembled polysomes are dynamically sequestered into SGs (Kedersha et al. 2000). Thus, SGs are thought to be sites of mRNA triage, a place where components of disassembled polysomes are sorted for silencing, reinitiation, or decay. Recent evidence suggests that the recruitment of specific proteins to SGs inhibits apoptosis (Arimoto et al. 2008) and affects cellular proliferation (Eisinger-Mathason et al. 2008), illustrating the critical role of SGs for cellular growth and survival.

Translational control at the level of initiation is an important mechanism of genetic regulation in eukaryotes, allowing cells to respond rapidly to environmental changes. Stress conditions activate stress-responsive kinases that inhibit translation initiation by phosphorylating the alphasubunit of the eukaryotic initiation factor 2 (eIF2 $\alpha)$. This phosphorylation event prevents GDP-GTP exchange on eIF2 by the guanine nucleotide exchange factor eIF2B, thereby inhibiting recycling of ternary complex containing

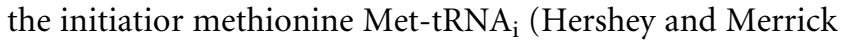
2000). Generally, the phosphorylation of eIF $2 \alpha$ results in polysome disassembly and subsequent SG assembly. However, SG formation can occur by P-eIF2 $\alpha$-independent mechanisms, when steps downstream from eIF2 $\alpha$ are inhibited. For instance, the drugs pateamine A and hippuristanol initiate SG formation by inhibiting RNA helicase 
eIF4A activity, thereby halting ribosome scanning and preventing further initiation events (Dang et al. 2006; Mazroui et al. 2006). By either mechanism, once new initiation events are inhibited, polysomes are disassembled and SGs can form. Thus, SGs and polysomes are in equilibrium, the balance shifting toward SGs when polysome disassembly becomes significant.

SGs have several defining characteristics: (1) SGs are reversible upon removal of the stress (Kedersha et al. 1999); (2) SGs contain poly (A) ${ }^{+}$RNA and components of the translation initiation machinery, but lack translating ribosomes (Kedersha et al. 2002); and (3) SG formation requires polysome disassembly (Kedersha et al. 2000). Until recently, bona fide SGs fitting all the above criteria were mainly reported in mammalian cells. However, several new studies have demonstrated the formation of SGs or SG-like bodies in Caenorhabditis elegans (Jud et al. 2008), Trypanosoma brucei (Kramer et al. 2008), Schizosaccharomyces pombe (Dunand-Sauthier et al. 2002), and Saccharomyces cerevisiae (Buchan et al. 2008; Groušl et al. 2009), although SGs have yet to be documented in some other common model organisms such as Xenopus laevis, Danio rerio, and Drosophila melanogaster. The apparent evolutionary conservation of SGs as a stress survival mechanism underscores their importance throughout eukaryota.

While much is known about the composition of SGs, the regulation of SG formation is not completely understood. In mouse cells, arsenite activates the heme-regulated inhibitor kinase HRI, and HRI-mediated phosphorylation of eIF $2 \alpha$ is essential for SG formation in response to arsenite (McEwen et al. 2005). However, SGs form in response to diverse stresses including heat shock, UV irradiation, and energy starvation caused by nutrient deprivation or mitochondrial poisons. It is not clear whether all of these stresses are P-eIF2 $\alpha$-dependent, or which kinases mediate eIF $2 \alpha$ phosphorylation under each specific stress condition.

Here we provide the first analysis of SG formation in response to arsenite and heat shock in Drosophila cells. The dynamics and composition of Drosophila SGs reveal their close relationship with mammalian SGs. However, while arsenite-induced SGs are dependent upon eIF2 $\alpha$ phosphorylation mediated primarily through the stress responsive kinase PEK, heat shock SGs form by a P-eIF2 $\alpha$-independent mechanism. In contrast, we report that heat-induced SGs are $\mathrm{P}$-eIF2 $\alpha$-dependent in mammalian cells, suggesting that flies and mammals utilize alternative mechanisms for responding to thermal stress.

\section{RESULTS AND DISCUSSION}

\section{Dynamic poly $(A)^{+}$RNA granules form in stressed Drosophila cells}

Given the importance of SGs in stress response pathways, we investigated SG occurrence in Drosophila. In untreated
$\mathrm{S} 2 \mathrm{R}+$ cells, poly $(\mathrm{A})^{+} \mathrm{RNA}$ is evenly distributed throughout the cytoplasm (Fig. 1A). Treatment with the SG-inducing drug arsenite for $1 \mathrm{~h}$ (Fig. 1A) or heat shock at $40^{\circ} \mathrm{C}$ or $42^{\circ} \mathrm{C}$ for $1 \mathrm{~h}$ (Fig. 1B) causes poly $(\mathrm{A})^{+}$RNA-containing granules to appear within the cytoplasm, appearing in $\sim 81 \%$ of arsenite-treated cells and $83 \%$ of cells at $40^{\circ} \mathrm{C}$ (Supplemental Fig. S1C). Arsenite treatment produces indentical results in a second Drosophila cell line Kc167 (data not shown), indicating that the granule formation is not specific to S2R+ cells. After $2 \mathrm{~h}$ of arsenite treatment, mRNA processing or export is inhibited, as evidenced by increased nuclear poly(A) ${ }^{+}$RNA (Fig. 1A; Supplemental Fig. S1A,B). Removing arsenite after $2 \mathrm{~h}$ of exposure allowed poly $(\mathrm{A})^{+}$RNA granules to dissolve within 2 to $3 \mathrm{~h}$. Interestingly, while granules formed at $40^{\circ} \mathrm{C}$ heat shock dissolve within $2 \mathrm{~h}$, those formed at $42^{\circ} \mathrm{C}$ heat shock do not (Fig. 1B).

Phosphorylation of eIF $2 \alpha$ is a hallmark of cellular stress and translational arrest. We assessed the phosphorylation state of eIF $2 \alpha$ in cells treated with arsenite or heat shock. One hour of arsenite treatment causes a marked increase in phosphorylated (P) -eIF2 $\alpha$ (Fig. 1C), which persists until the SGs are fully dissolved at $3 \mathrm{~h}$ post-removal of the drug. While P-eIF $2 \alpha$ levels are slightly increased after $37^{\circ} \mathrm{C}$ or $40^{\circ} \mathrm{C}$ heat shock, P-eIF $2 \alpha$ is decreased dramatically at $42^{\circ} \mathrm{C}$ (Fig. 1D). It is possible that phosphorylation is totally inhibited at this temperature, or that eIF $2 \alpha$ is phosphorylated early during the stress and subsequently dephosphorylated. To distinguish between these two possibilities, cells were subjected to $40^{\circ} \mathrm{C}$ or $42^{\circ} \mathrm{C}$ heat shock and samples were taken for Western blot every $15 \mathrm{~min}$ to assess for P-eIF2 $\alpha$ (Fig. 1E). In fact, eIF2 $\alpha$ is phosphorylated within $15 \mathrm{~min}$ of heat shock. This phosphorylation peaks at $30 \mathrm{~min}$, then decreases after $1 \mathrm{~h}$ of heat shock.

To determine whether the decrease in P-eIF2 $\alpha$ was due to rapid dephosphorylation or to degradation of eIF $2 \alpha$, cells were pretreated with okadaic acid (OA), a potent phosphatase inhibitor, or the proteasome inhibitor MG132, for $3 \mathrm{~h}$ and then heat-shocked at $40^{\circ} \mathrm{C}$ or $42^{\circ} \mathrm{C}$ for $1 \mathrm{~h}$ (Fig. $1 F)$. While MG132 had little or no effect on P-eIF2 $\alpha$ levels, OA significantly stabilized P-eIF $\alpha$ at $40^{\circ} \mathrm{C}$ and $42^{\circ} \mathrm{C}$. MG132 treatment is efficient in these cells, as shown by accumulation of higher molecular weight ubiquitin conjugates (Fig. 1G). Thus, eIF2 $\alpha$ is rapidly dephosphorylated under conditions of moderate to severe heat shock.

Notably, P-eIF2 $\alpha$ levels in the heat shock time courses peak at $30 \mathrm{~min}$, the time at which heat shock-induced $\operatorname{poly}(\mathrm{A})^{+}$RNA granules begin to form (data not shown). In contrast, arsenite induces sustained P-eIF2 $\alpha$ levels that do not decrease until the stress is removed and SGs are dissolved (Fig. 1A,C). It seems therefore that, while P-eIF2 $\alpha$ levels are well correlated with poly $(\mathrm{A})^{+}$RNA granule formation under arsenite stress, P-eIF $2 \alpha$ is not correlated with the formation of heat-induced granules, suggesting that heat shock and P-eIF $2 \alpha$ are uncoupled in the Drosophila system. 

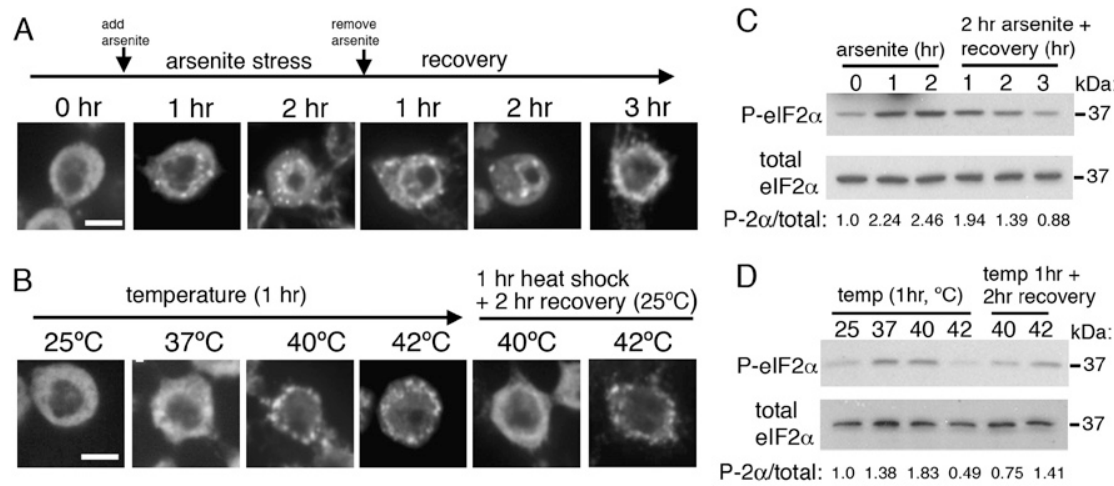

E
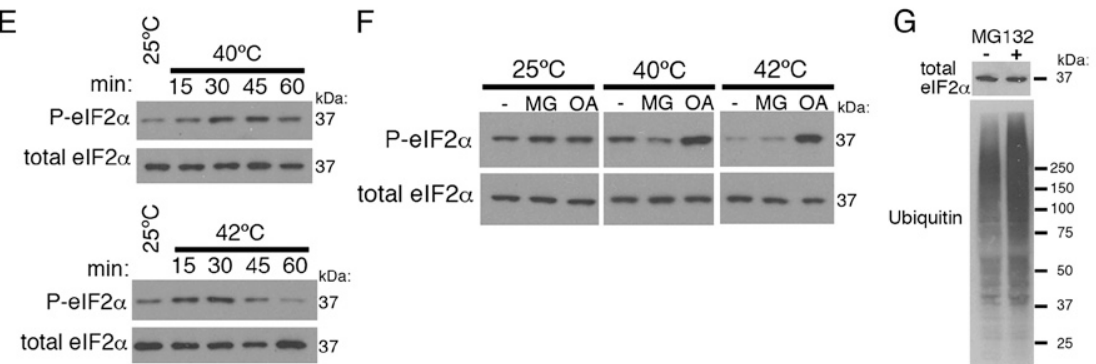

FIGURE 1. Arsenite or heat shock causes the formation of reversible, cytoplasmic, poly $(\mathrm{A})^{+}$ RNA granules in Drosophila cells. (A) $500 \mu \mathrm{M}$ arsenite was applied to S2R+ cells for times indicated, or applied for $2 \mathrm{~h}$ then removed and recovered for times indicated, then cells were fixed and hybridized with Cy3-Oligo-dT(30) to visualize poly(A) ${ }^{+}$RNA. (B) S2R+ cells were incubated at the indicated temperatures for $1 \mathrm{~h}$, or incubated for $1 \mathrm{~h}$ followed by $2 \mathrm{~h}$ of recovery, then processed for RNA visualization as in $A$. Bars, $5 \mu \mathrm{m}$. $(C, D)$ Western blots of arsenite $(C)$ and heat shock $(D)$ time course samples, parallel to those shown in $A$ and $B$, respectively. P- $2 \alpha /$ total is the ratio of the density of the P-eIF $2 \alpha$ bands divided by total eIF $2 \alpha$ bands, normalized to the control lane. $(E) \mathrm{S} 2 \mathrm{R}+$ cells were heat-shocked as indicated, and then processed for Western blot. (F) S2R+ cells were pre-incubated with MG132 (MG) at $100 \mu \mathrm{M}$ for $3 \mathrm{~h}$, or $75 \mathrm{~nm}$ of okadaic acid (OA) for $3 \mathrm{~h}$, then heat-shocked for $1 \mathrm{~h}$ and processed for Western blot. $(G)$ A replicate of the $-/+\mathrm{MG} 132,25^{\circ} \mathrm{C}$ samples from panel $F$ (lanes 1,2 ) was processed for Western blot and probed with anti-ubiquitin antibody.

\section{Drosophila stress-induced poly $(\mathrm{A})^{+}$RNA granules contain homologs of mammalian SG factors}

In order to determine that Drosophila poly $(\mathrm{A})^{+}$RNA granules were in fact bona fide SGs, we co-localized the granules with known SG markers. The human fragile X mental retardation proteins FMRP and FXR1 localize to mammalian SGs (Mazroui et al. 2002; Linder et al. 2008). We assessed the localization of the Drosophila homolog FMR1 in stressed cells, and found that FMR1 and poly $(\mathrm{A})^{+}$ RNA are co-localized in cytoplasmic granules after exposure to arsenite or $40^{\circ} \mathrm{C}$ heat shock (Fig. 2A). Processing bodies (PBs) are constitutive cytoplasmic granules that are sites of mRNA silencing and decay (Eulalio et al. 2007) and that increase in size and frequency during stress (Kedersha et al. 2005). Co-staining of arsenite-treated or heat-shocked cells with FMR1 and DCP1, an endogenous marker of PBs, revealed that FMR1-containing granules are largely distinct from, but often adjacent to, PBs (Fig. 2B). This juxtaposition of cytoplasmic bodies precisely mirrors the relationship between SGs and PBs in mammalian cells (Kedersha et al. 2005; Wilczynska et al. 2005), suggesting that
Drosophila SGs and PBs exist in a similar dynamic relationship whereby protein and mRNA components are shuttled between the two bodies.

Under arsenite or heat shock conditions, FMR1 co-localizes in cytoplasmic granules with other known SG components including endogenous eIF4E (Fig. 2E), and with exogenous V5-eIF3 S9 (eIF3b) (Fig. 2F), GFP-PABP (Fig. 2G), and GFP-Rox8 (Fig. 2H). Rox8 is the Drosophila homolog of TIA-1, one of the first mammalian proteins found to localize to SGs (Kedersha et al. 1999), and shown to regulate their formation by auto-aggregation (Gilks et al. 2004). Notably, FMR1 does not co-localize with the large ribosomal subunit protein RPL P0 in stressed cells (Fig. 2C; Supplemental Fig. S2A), but does colocalize with the 18S rRNA of the small ribosomal subunit (Fig. 2D; Supplemental Fig. S2B). These data are consistent with the idea that these granules are comprised of arrested translational initiation complexes and disassembled polysome components, and contain $40 \mathrm{~S}$ but not $60 \mathrm{~S}$ ribosomes. Thus, the components of Drosophila poly(A) ${ }^{+}$RNAcontaining granules are consistent with those of mammalian SGs.

SGs exist in equilibrium with polysomes in mammalian cells, and polysome disassembly is required for SG formation (Kedersha et al. 2000). To assess Drosophila stress-induced poly(A) ${ }^{+}$ RNA granules for this functional criterion, we analyzed polysome profiles from stressed cells. S2R+ cells were pretreated with the translation elongation inhibitor cyclohexamide $(\mathrm{CHX})$, which prevents ribosome dissociation from mRNA, or left untreated, and then followed by arsenite or heat shock. Arsenite treatment induced P-eIF $2 \alpha$ (Fig. 3D, lane 2), and caused polysome disassembly (Fig. 3A). Pretreatment of cells with CHX inhibited polysome disassembly (Fig. 3B) and inhibited the formation of granules upon arsenite treatment (Fig. 3C) but did not prevent eIF2 $\alpha$ phosphorylation (Fig. 3D, lane 4 ), nor did it prevent the nuclear RNA accumulation seen in arsenitetreated cells (Fig. 3C, panel 4). In fact, P-eIF2 $\alpha$ is undetectable in cycloheximide-treated cells, which may be an attempt by the cell to compensate for the translational arrest caused by the drug. We conclude that arseniteinduced polysome disassembly is required for $\operatorname{poly}(\mathrm{A})^{+}$ RNA granule formation.

Similarly, heat shock-induced polysome disassembly (Fig. 3E) was also blocked by CHX pretreatment (Fig. 3F), 

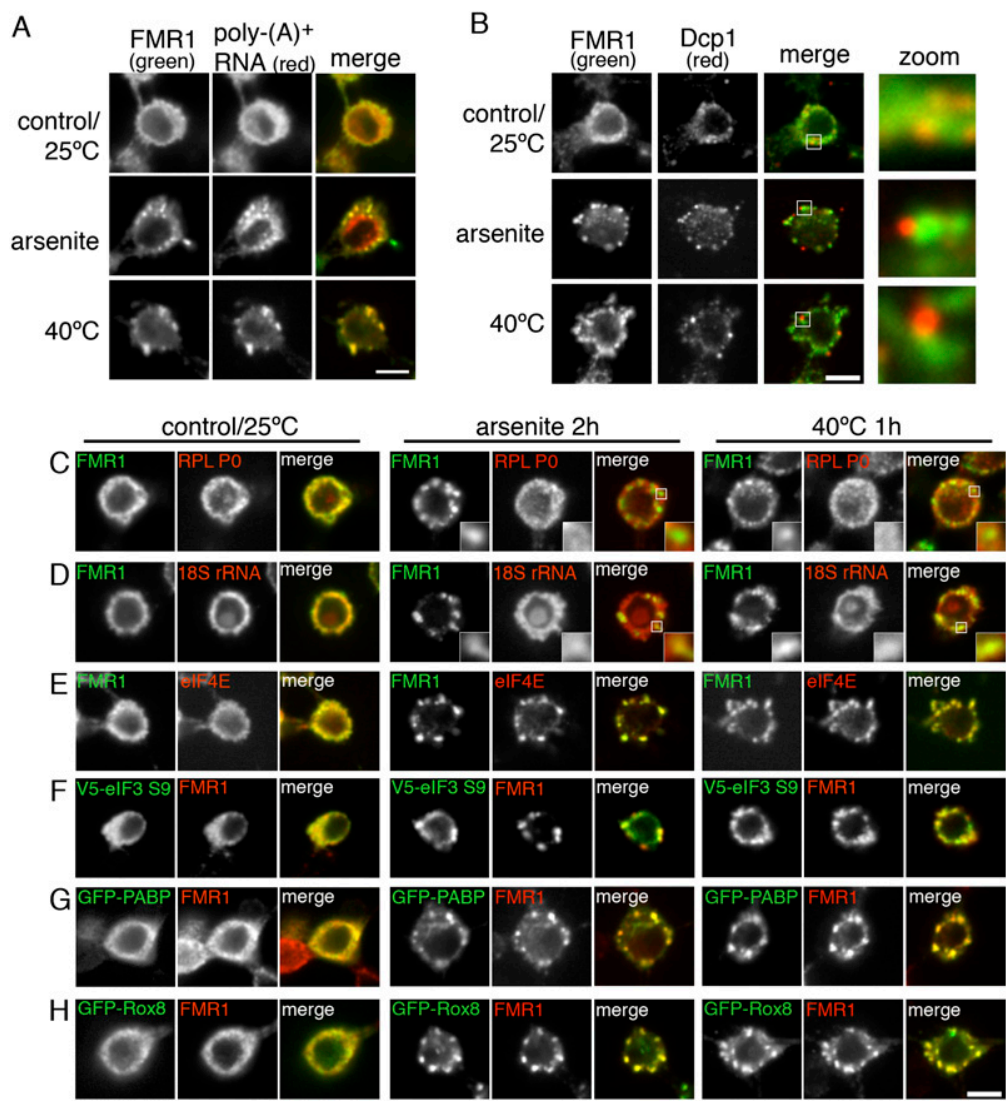

FIGURE 2. Stress-induced, poly(A) ${ }^{+}$RNA granules co-localize with markers of SGs. (A) S2R+ cells were stressed with $500 \mu \mathrm{m}$ arsenite for $2 \mathrm{~h}$, or heat shock at $40^{\circ} \mathrm{C}$ for $1 \mathrm{~h}$, or left untreated, then fixed and hybridized with Cy3-Oligo-dT(30) (red, center panels). Then, cells were costained with antibodies to FMR1 (green, left panels). (B) After stress treatment as in A, cells were fixed and co-stained with antibodies to FMR1 (green, left panels) and Dcp1 (red, center panels). White boxes indicate regions enlarged at right. $(C, E)$ Control or stressed cells were stained with antibodies to RPL P0 $(C$, red) or eIF4E ( $E$, red) and co-stained with anti-FMR1 (green). (D) Control or stressed cells were hybridized with a Cy3-labeled probe specific for $18 \mathrm{~S}$ rRNA and co-stained with anti-FMR1. A second, nonoverlapping probe yielded identical results (data not shown). White boxes in arsenite and heat shock "merge" panels of $C$ and $D$ indicate areas enlarged in the lower right hand corners of these panels. $(F-H) \mathrm{S} 2 \mathrm{R}+$ cells were transfected with V5-eIF3 S8 $(F)$, GFP-PABP $(G)$, or GFP-Rox8 $(H)$, and co-stained with antiFMR1 (red). Bars, $5 \mu \mathrm{m}$.

as was the formation of poly(A) ${ }^{+}$RNA granules (Fig. 3G). P-eIF2 $\alpha$ was slightly elevated in the heat shock samples as seen previously (Fig. $3 \mathrm{H}$ ), and this was not affected by CHX treatment. Taken together, the results of Figures 1, 2, and 3 demonstrate the dynamic formation of stress-induced cytoplasmic granules in Drosophila cells consistent with the defining characteristics of mammalian SGs. Hereafter we will refer to these Drosophila granules as SGs.

\section{Arsenite SGs, but not heat shock SGs, require P-eIF2 $\alpha$ in Drosophila}

Mammalian cells have four eIF2 $\alpha$ kinases: GCN2, PEK/ PERK, PKR, and HRI. Drosophila, however, have only two eIF2 $\alpha$ kinases: GCN2 and PEK. To assess which Drosophila eIF2 $\alpha$ kinase mediates SG formation in response to arsenite or heat shock, we used double-stranded (ds)RNA to deplete cells of either or both kinases, then assessed whether the depleted cells could form SGs. S2R+ cells were treated with dsRNAs targeting PEK, GCN2, or both, for $4 \mathrm{~d}$, then exposed to arsenite or heat shock. Quantitative real-time PCR was used to monitor the knockdown efficiency of the PEK and GCN2 dsRNAs (Fig. 4C). At $4 \mathrm{~d}$ of dsRNA treatment, PEK and GCN2 mRNAs were depleted to $10 \%$ and $15 \%$ of control GFP dsRNA-treated levels, respectively.

When treated with a negative control dsRNA targeting GFP, $\sim 70 \%$ of cells responded to arsenite by forming SGs (Fig. 4A). Upon knockdown of PEK, only $\sim 40 \%$ of cells exhibited SGs, whereas GCN2 knockdown reduced SG formation to $\sim 50 \%$. Strikingly, double depletion of PEK and GCN2 reduced SG formation to $<25 \%$. Western blot analysis of parallel samples revealed that knockdown of PEK had a more significant effect on reducing P-eIF2 $\alpha$ in arsenite treated cells, whereas GCN2 knockdown had only a modest effect (Fig. 4B, center panel). This result suggests that PEK is the main eIF2 $\alpha$ kinase activated by arsenite, whereas GCN2 plays a more secondary role.

After heat shock, $\sim 95 \%$ of control GFP dsRNA-treated cells form SGs. This percentage was not significantly affected by knockdown of either or both of the eIF2 $\alpha$ kinases (Fig. 4A). As in previous experiments, a modest increase in P-eIF2 $\alpha$ was seen upon heat shock (Fig. 4B, right panel), and this amount was almost entirely eliminated by PEK or double PEK/GCN2 knockdown. The elimination of P-eIF2 $\alpha$ did not affect SG formation in response to heat shock, suggesting that heat shock mediates SG fomation independently of P-eIF2 $\alpha$ in Drosophila cells.

\section{Mammalian heat shock SG assembly is P-elF2 $\alpha$-dependent}

Our Drosophila results suggest that robust heat shock activates a P-eIF2 $\alpha$-independent stress response resulting in SG assembly. To determine whether heat shock-induced SGs are P-eIF2 $\alpha$-independent in mammalian cells, we asked whether heat shock could induce SG formation in murine embryonic fibroblasts (MEFs) containing a nonphosphorylatable mutant form (Ser51Ala) of eIF2 $\alpha$ (Scheuner 

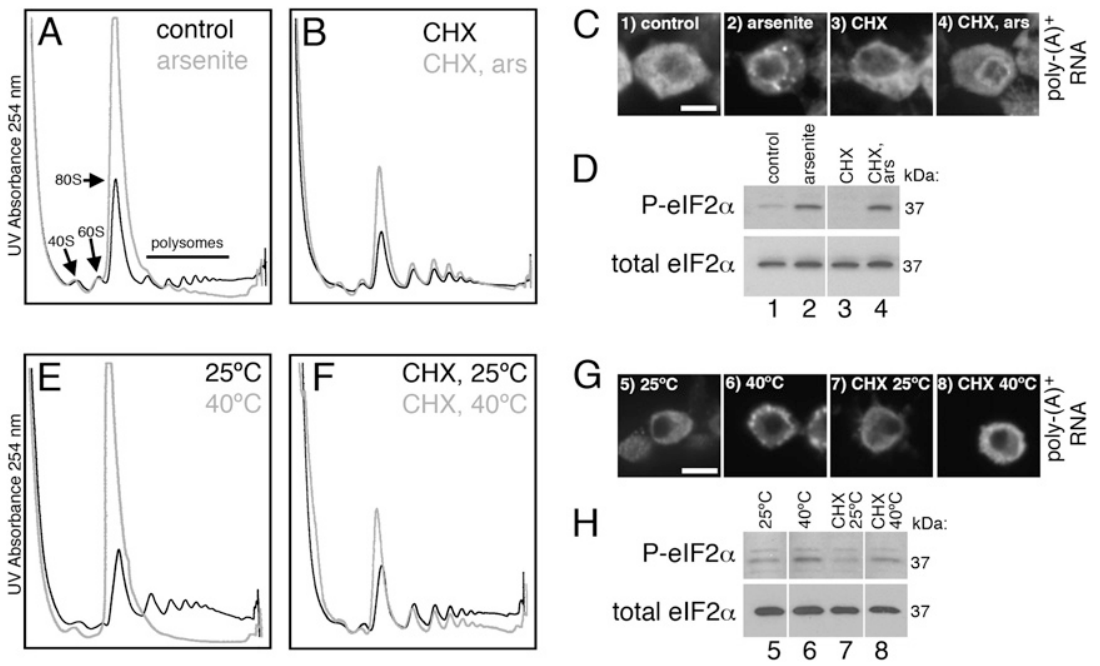

FIGURE 3. Polysome disassembly is required for the formation of Drosophila SGs. $(A, B, E, F)$ Sucrose gradient analysis of polysomes. S2R+ cells were untreated $(A, E$, black traces) or treated with $500 \mu \mathrm{M}$ arsenite $\left(A\right.$, gray trace) or heat shock at $40^{\circ} \mathrm{C}$ for $1 \mathrm{~h}$ ( $E$, gray trace). Where indicated, cells were treated with CHX $(50 \mu \mathrm{g} / \mathrm{mL})$ for $3 \mathrm{~h}(B, F$, black traces) or pretreated with CHX for $2 \mathrm{~h}$ followed by $1 \mathrm{~h}$ of arsenite $\left(B\right.$, gray trace) or heat shock at $40^{\circ} \mathrm{C}(F$, gray trace). $(C, G)$ Parallel samples to those in $A-B$ and $E-F$ were hybridized with Cy3-Oligo-dT(30) to visualize SGs. Bars, $5 \mu \mathrm{m}$. $(D, H)$ Western blots of parallel samples to those in $C$ and $G$. Bands shown are from the same film and exposure for each antibody; Intermediate lanes containing irrelevant samples were removed for simplicity.

et al. 2001). Ser51Ala MEFs were co-plated with humanderived U2OS cells containing wild-type eIF2 $\alpha$, then heatshocked for $30 \mathrm{~min}$. While wild-type MEFs (data not shown) and U2OS cells form robust SGs at $44^{\circ} \mathrm{C}$ (data not shown) and at $48^{\circ} \mathrm{C}$ (Fig. $4 \mathrm{D}$, top panels) containing eIF3b and eIF4E, the Ser51Ala MEFs did not form SGs. Other SG markers (data not shown) including FXR1, FXR2, TIA-1, G3BP, and eIF4G showed identical results. Pretreatment of the cells with CHX inhibits heat-induced SGs in the U2OS cells (Fig. 4D, center panels). To insure that the Ser51Ala MEFs are not impaired in other posttranslational steps linked to SG assembly downstream from polysome disassembly such as O-GlcNAc modification, ubiquitinylation, or motor proteins (for review, see Anderson and Kedersha 2008), we treated the cells with pateamine A, which induces SG formation independently of P-eIF2 $\alpha$. Pateamine A treatment revealed that the Ser51Ala MEFs are fully competent for SG assembly (Fig. 4D, bottom panels). Thus, while heat shock may be a P-eIF $2 \alpha$-independent stress in Drosophila, mammalian cells require P-eIF2 $\alpha$ for the formation of heat shock SGs.

While heat-induced SG formation has been studied in several organisms, the specific role of P-eIF2 $\alpha$ in responding to heat shock has only partially been addressed. A recent study in S. cerevisiae indicated that yeast heat shock SGs are not regulated by eIF2 $\alpha$ phosphorylation, as deletion of the sole yeast eIF2 $\alpha$ kinase, Gcn2p, did not inhibit SG formation (Groušl et al. 2009). Similarly, heatinduced SGs in trypanosomes are also eIF2 $\alpha$-independent
(Kramer et al. 2008), as mutant trypanosomes with an eIF2 $\alpha$ Thr169Ala mutation still formed SGs in response to heat shock. Thr169 is thought to be functionally analogous to Ser51 in other eukaryotes, although it has not yet been directly demonstrated that phosphorylation of trypanosome eIF2 $\alpha$ at Thr169 is a physiologically relevant mode of translational control in response to stress in this organism.

The results of Figure 4 indicate that heat shock SGs are P-eIF2 $\alpha$-independent in Drosophila, but are P-eIF2 $\alpha$-dependent in mammalian cells. What is the source of this difference? We propose that metabolic control of thermoregulation may lie at the heart of this question. Drosophila, yeast, and trypanosomes are ectothermic organisms that must display a significant range of thermal tolerance in order to adapt to the temperature of their environment. Mammals utilize vast cellular resources to maintain an optimal internal temperature, and it is therefore critical for their heat stress response pathways to be tightly regulated. Somewhere during the evolution of thermogenesis in mammals, the heat shock response may have become tied into translational control pathways via one or several of the eIF2 $\alpha$ kinases, providing an additional means for genetic regulation during heat stress.

In summary, this work provides the first analysis of Drosophila SGs. We show that Drosophila has at least two different mechanisms for SG formation: a P-eIF2 $\alpha$-dependent mechanism activated by arsenite primarily via PEK, and a P-eIF2 $\alpha$-independent mechanism activated by heat shock (Fig. 4E). Additionally, we show heat shock SG formation is $\mathrm{P}$-eIF2 $\alpha$-dependent in mammalian cells, suggesting that a more direct connection between heat shock and eIF $2 \alpha$ arose during evolution, possibly concurrent with the development of thermogenesis.

\section{MATERIALS AND METHODS}

\section{Reagents, cell lines, and plasmids}

$\mathrm{S} 2 \mathrm{R}+$ cells were cultured at $25^{\circ} \mathrm{C}$ in Schneider's Drosophila medium (Invitrogen) supplemented with 10\% fetal bovine serum and penicillin/streptomycin. Coding regions of eIF3 S9, PABP, and Rox8 were amplified from S2R+ cDNA, and inserted in frame into pAc5.1-GFP at the $3^{\prime}$ end of the EGFP coding region (for PABP and Rox8), or into pAc5.1 in frame with the V5/His tag (for eIF3 S9) as previously described (Farny et al. 2008) using the primers listed in Supplemental Table S1. Sodium meta-arsenite, MG132, and cycloheximide were purchased from Sigma Aldrich. Okadaic acid was purchased from Calbiochem. DMDA-pateamine 
A

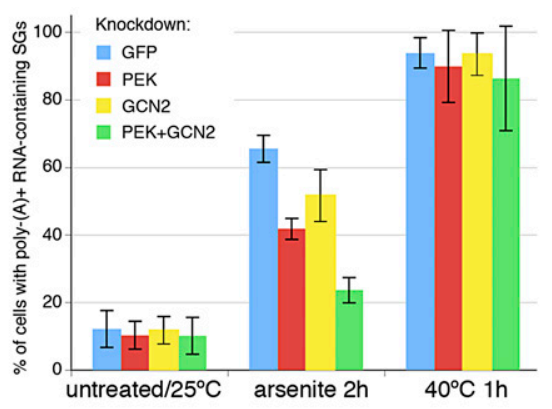

$\mathrm{B}$

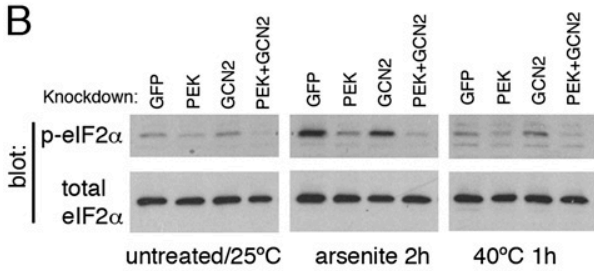

C

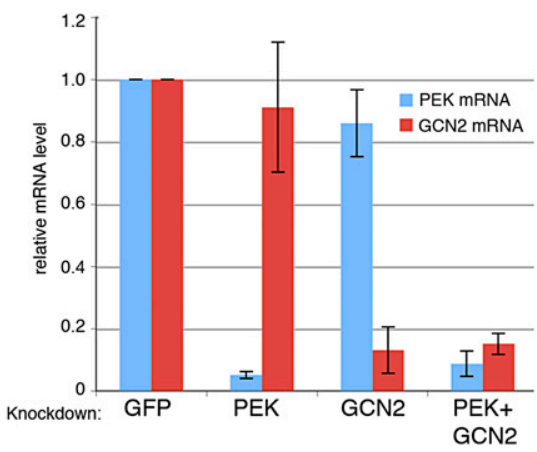

D

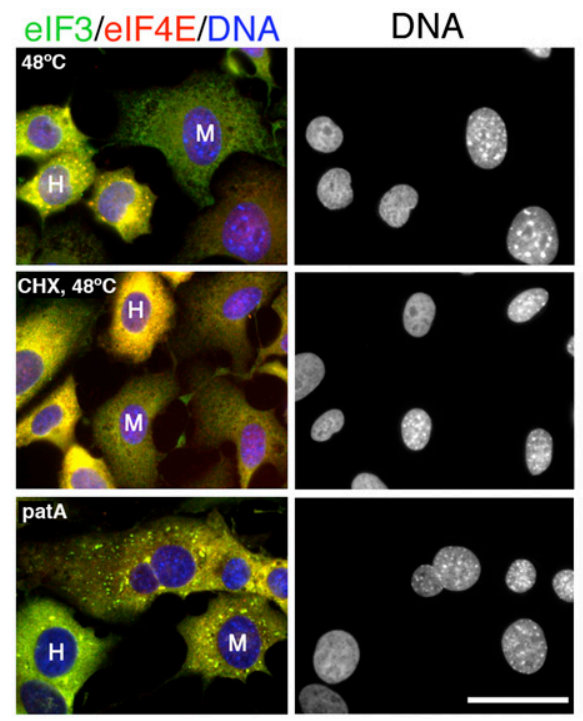

E

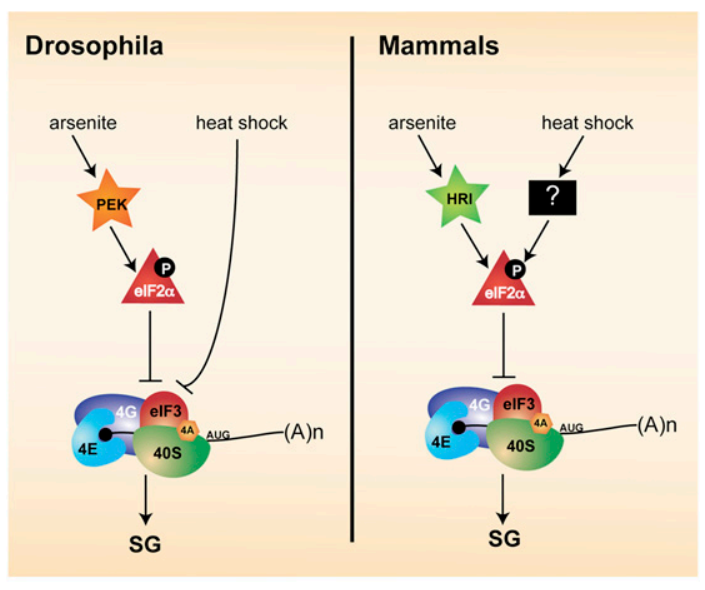

FIGURE 4. P-eIF2 $\alpha$ is required for heat shock SGs in mammals, but not in flies. (A) S2R+ cells were treated with indicated dsRNAs for 96 h, followed by $500 \mu \mathrm{m}$ arsenite for $2 \mathrm{~h}$ or $40^{\circ} \mathrm{C}$ heat shock for $1 \mathrm{~h}$, then hybridized with Cy3-Oligo-dT(30). Samples were blinded and photographed, and cells in each image were scored for the presence of SGs. $(B)$ Western blot of parallel samples to the data shown in $A$. (C) Quantitative realtime PCR analysis of PEK and GCN2 mRNA levels in knockdown cells. Error bars in $A$ and $C$ represent one standard deviation from the average of three independent experiments. (D) eIF2 $\alpha$ Ser51Ala MEFs (denoted "M") were co-plated with human-derived U2OS cells (denoted " $H$ "), then either exposed to heat shock at $48^{\circ} \mathrm{C}$ for $30 \mathrm{~min}$ (top panels), pre-treated with CHX at $50 \mu \mathrm{g} / \mathrm{mL}$ for 30 min, and then heat-shocked (center panels), or treated with $50 \mu \mathrm{M}$ pateamine A (patA) for $1 \mathrm{~h}$ (bottom panels). Samples were fixed and stained with anti-eIF3 (green), anti-eIF4E (red), and Hoechst (DNA, blue). Mouse cells can be distinguished from human cells by the distinct nuclear speckling pattern in DNA panels. Bar, $25 \mu \mathrm{m}$. (E) A model of eIF2 $\alpha$-dependent and -independent translational arrest and SG formation in Drosophila and mammals. In Drosophila, arsenite results in the phosphorylation of eIF2 $\alpha$ via the kinase PEK, whereas in mammals the critical arsenite responsive kinase is HRI. In both cases, P-eIF2 $\alpha$ inhibits translation initiation, and the initiation complex, associated mRNAs and RNA binding proteins are recruited to SGs. However, the formation of Drosophila heat shock SGs does not depend on P-eIF2 $\alpha$, whereas P-eIF2 $\alpha$ is required for mammalian heat shock SGs. The mammalian eIF2 $\alpha$ kinase(s) activated by heat shock is unknown.

A was a kind gift from Jun Liu (Johns Hopkins University). For transient transfections, S2R+ cells were transfected with Effectine (Qiagen) per the manufacturer's protocols as described (Farny et al. 2008). Cells were processed $\sim 20$ h post-transfection.

\section{dsRNA production and RNAi}

dsRNAs were produced as described (Farny et al. 2008) based on amplicons designed by the Drosophila RNAi Screening Center at Harvard Medical School (http://flyrnai.org). DNA amplicons for dsRNA templates were amplified from S2R+ cDNA (or for GFP
dsRNA, from the plasmid pAc5.1-GFP) using the primers listed in Supplemental Table S1. RNAi assays were performed essentially as described (Farny et al. 2008). Briefly, $1.5 \times 10^{6}$ cells were plated in $300 \mu \mathrm{L}$ serum free media; $8 \mu \mathrm{g}$ dsRNA were added and incubated for $30 \mathrm{~min}$. Cells were then supplemented with $900 \mu \mathrm{L}$ complete culture media and incubated at $25^{\circ} \mathrm{C}$ for $\sim 4 \mathrm{~d}$.

\section{SG formation assay}

After dsRNA treatment as described above, S2R+ cells were stresstreated, scrape-harvested, and processed for poly $(\mathrm{A})^{+}$fluorescence 
in situ hybridization (FISH). Coverslips containing experimental samples were mounted on individual slides, and slides were then blinded, imaged, and scored. At least four fields and at least 100 cells were imaged for each blinded sample. The cells in the images were then counted manually as SG-positive or SG-negative. SGs are generally $0.2-1.0 \mu \mathrm{m}$ in diameter and vary widely from 4 to 15 or more per cell. An individual cell had to contain at least three poly $(\mathrm{A})^{+}$granules of typical SG size to be counted as positive. The experiment was repeated three times. Similar results were obtained when using anti-FMR1 antibody as a SG marker instead of poly $(\mathrm{A})^{+}$RNA.

\section{Immunofluorescence staining and in situ hybridization}

After transfection and/or drug treatment, S2R+ cells were fixed in $2 \%$ paraformaldehyde in PBS $+0.5 \%$ TX-100 for 5 min, then $4 \%$ paraformaldehyde in PBS for $10 \mathrm{~min}$. Antibody staining or in situ hybridization was performed on fixed cells as described (Farny et al. 2008). Immunofluorescence of mammalian cells was performed as described (Kedersha et al. 2005). Antibodies for immunofluorescence microscopy were obtained as follows: rabbitanti-deIF4E was a kind gift from P. Lasko (McGill University); rabbit-anti-Dcp1 was a kind gift from J. Lykke-Andersen (University of Colorado); human-anti-ribosomal protein P0 (ImmunoVision); rabbit-anti-V5 (Sigma Aldrich); goat-anti-dFMR1, goatanti-eIF3b, and mouse-anti-eIF4E (Santa Cruz Biotechnology); donkey-anti-rabbit Cy2, donkey-anti-mouse Cy2, donkey-anti-goat Cy2, donkey-anti-goat Cy3 (Jackson ImmunoResearch); Alexa488WGA (Invitrogen); Cy3-Oligo-dT(30) and Cy3-18S rRNA probes ( $1 \mathrm{mg} / \mathrm{mL}$, Integrated DNA Technologies). Probe sequences for Cy3-18S rRNA probes are listed in Supplemental Table S1. Images of S2R+ cells were taken on a Nikon TE2000 inverted fluorescence microscope with $3 \mathrm{~W}$ laser spinning disk confocal and a 100x PlanApo lens, acquired with a digital camera (Hamamatsu) and processed using MetaMorph software (Molecular Devices). Images shown are single $\mathrm{Z}$-sections. Images of mammalian cells were taken on a wide-field fluorescence microscope (model Eclipse E800; Nikon) with epifluorescence optics, a $60 \mathrm{X}$ oil immersion lens, and a digital camera (model CCD-SPOT RT; Diagnostic Instruments). All images were compiled for figures using Adobe Photoshop CS3 software.

\section{Western blot analysis}

Western blots were performed as described (Farny et al. 2008). Antibodies for Western blot were used at the following dilutions: rabbit-anti-eIF2 $\alpha$ P-ser52 (Abcam), 1:1000; rabbit-anti-eIF2 $\alpha$ (Abcam), 1:1000; mouse-anti-ubiquitin (Santa Cruz Biotechnology), 1:1000; donkey-anti-rabbit (light chain specific) horseradish peroxidase (HRP) or donkey-anti-mouse HRP (Jackson ImmunoResearch), 1:5000. Band densitrometry was performed using Quantity One software (Bio-Rad).

\section{Sucrose gradient analysis of polysomes}

Polysome analysis was performed as described (Farny et al. 2008), with the following changes: after arsenite or heat shock treatment, cells were incubated in $100 \mu \mathrm{g} / \mathrm{mL}$ cycloheximide for $10 \mathrm{~min}$, then pelleted and lysed in polysome lysis buffer containing RNase inhibitors.

\section{Quantitative real-time PCR}

Quantitative real-time PCR was performed and analyzed as described (Farny et al. 2008) using the primer sets listed in Supplemental Table S1.

\section{SUPPLEMENTAL MATERIAL}

Supplemental material can be found at http://www.rnajournal.org.

\section{ACKNOWLEDGMENTS}

We thank J. Lykke-Andersen and P. Lasko for the antibodies, J. Lui for DMDA-PatA, J. Hurt for critical reading of this manuscript, and the members of the Silver and Anderson laboratories for advice and support. This work was supported by NIH grant GM057476 to P.A.S. N.L.K. was supported by NIH RO1 AI 033600 .

Received April 9, 2009; accepted June 30, 2009.

\section{REFERENCES}

Anderson P, Kedersha N. 2006. RNA granules. J Cell Biol 172: 803808.

Anderson P, Kedersha N. 2008. Stress granules: The Tao of RNA triage. Trends Biochem Sci 33: 141-150.

Arimoto K, Fukuda H, Imajoh-Ohmi S, Saito H, Takekawa M. 2008. Formation of stress granules inhibits apoptosis by suppressing stress-responsive MAPK pathways. Nat Cell Biol 10: 1324-1332.

Buchan JR, Muhlrad D, Parker R. 2008. P bodies promote stress granule assembly in Saccharomyces cerevisiae. J Cell Biol 183: 441455.

Dang Y, Kedersha N, Low WK, Romo D, Gorospe M, Kaufman R, Anderson P, Liu JO. 2006. Eukaryotic initiation factor $2 \alpha-$ independent pathway of stress granule induction by the natural product pateamine A. J Biol Chem 281: 32870-32878.

Dunand-Sauthier I, Walker C, Wilkinson C, Gordon C, Crane R, Norbury C, Humphrey T. 2002. Sum1, a component of the fission yeast eIF3 translation initiation complex, is rapidly relocalized during environmental stress and interacts with components of the 26 S proteasome. Mol Biol Cell 13: 1626-1640.

Eisinger-Mathason TS, Andrade J, Groehler AL, Clark DE, MuratoreSchroeder TL, Pasic L, Smith JA, Shabanowitz J, Hunt DF, Macara IG, et al. 2008. Codependent functions of RSK2 and the apoptosis-promoting factor TIA-1 in stress granule assembly and cell survival. Mol Cell 31: 722-736.

Eulalio A, Behm-Ansmant I, Izaurralde E. 2007. P bodies: At the crossroads of post-transcriptional pathways. Nat Rev Mol Cell Biol 8: 9-22.

Farny NG, Hurt JA, Silver PA. 2008. Definition of global and transcript-specific mRNA export pathways in metazoans. Genes \& Dev 22: 66-78.

Gilks N, Kedersha N, Ayodele M, Shen L, Stoecklin G, Dember LM, Anderson P. 2004. Stress granule assembly is mediated by prionlike aggregation of TIA-1. Mol Biol Cell 15: 5383-5398.

Groušl T, Ivanov P, Frydlová I, Vašicová P, Janda F, Vojtová J, Malínská K, Malcová I, Nováková L, Janošková D, et al. 2009. Robust heat shock induces eIF $2 \alpha$-phosphorylation-independent assembly of stress granules containing eIF3 and 40S ribosomal subunits in budding yeast, Saccharomyces cerevisiae. J Cell Sci 122: 2078-2088.

Hershey JWB, Merrick WC. 2000. Pathway and mechanism of initiation of protein synthesis. In Translational control of gene 
expression. (eds. N Sonenberg et al.), pp. 33-88. Cold Spring Harbor Laboratory Press, Cold Spring Harbor, New York.

Jud MC, Czerwinski MJ, Wood MP, Young RA, Gallo CM, Bickel JS, Petty EL, Mason JM, Little BA, Padilla PA, et al. 2008. Large P body-like RNPs form in C. elegans oocytes in response to arrested ovulation, heat shock, osmotic stress, and anoxia and are regulated by the major sperm protein pathway. Dev Biol 318: 38-51.

Kedersha NL, Gupta M, Li W, Miller I, Anderson P. 1999. RNAbinding proteins TIA- 1 and TIAR link the phosphorylation of eIF$2 \alpha$ to the assembly of mammalian stress granules. J Cell Biol 147: 1431-1442.

Kedersha N, Cho MR, Li W, Yacono PW, Chen S, Gilks N, Golan DE, Anderson P. 2000. Dynamic shuttling of TIA-1 accompanies the recruitment of mRNA to mammalian stress granules. J Cell Biol 151: $1257-1268$.

Kedersha N, Chen S, Gilks N, Li W, Miller IJ, Stahl J, Anderson P. 2002. Evidence that ternary complex (eIF2-GTP-tRNA $A_{i}^{\text {Met }}$ )-deficient preinitiation complexes are core constituents of mammalian stress granules. Mol Biol Cell 13: 195-210.

Kedersha N, Stoecklin G, Ayodele M, Yacono P, Lykke-Andersen J, Fritzler MJ, Scheuner D, Kaufman RJ, Golan DE, Anderson P. 2005. Stress granules and processing bodies are dynamically linked sites of mRNP remodeling. J Cell Biol 169: 871-884.

Kiebler MA, Bassell GJ. 2006. Neuronal RNA granules: Movers and makers. Neuron 51: 685-690.

Kramer S, Queiroz R, Ellis L, Webb H, Hoheisel JD, Clayton C, Carrington M. 2008. Heat shock causes a decrease in polysomes and the appearance of stress granules in trypanosomes indepen- dently of eIF2 $\alpha$ phosphorylation at Thr169. J Cell Sci 121: 30023014.

Linder B, Plottner O, Kroiss M, Hartmann E, Laggerbauer B, Meister G, Keidel E, Fischer U. 2008. Tdrd3 is a novel stress granule-associated protein interacting with the Fragile- $\mathrm{X}$ syndrome protein FMRP. Hum Mol Genet 17: 3236-3246.

Mazroui R, Huot ME, Tremblay S, Filion C, Labelle Y, Khandjian EW. 2002. Trapping of messenger RNA by fragile X mental retardation protein into cytoplasmic granules induces translation repression. Hum Mol Genet 11: 3007-3017.

Mazroui R, Sukarieh R, Bordeleau ME, Kaufman RJ, Northcote P, Tanaka J, Gallouzi I, Pelletier J. 2006. Inhibition of ribosome recruitment induces stress granule formation independently of eukaryotic initiation factor $2 \alpha$ phosphorylation. Mol Biol Cell 17: 4212-4219.

McEwen E, Kedersha N, Song B, Scheuner D, Gilks N, Han A, Chen JJ, Anderson P, Kaufman RJ. 2005. Heme-regulated inhibitor kinase-mediated phosphorylation of eukaryotic translation initiation factor 2 inhibits translation, induces stress granule formation, and mediates survival upon arsenite exposure. J Biol Chem 280: 16925-16933.

Scheuner D, Song B, McEwen E, Liu C, Laybutt R, Gillespie P, Saunders T, Bonner-Weir S, Kaufman RJ. 2001. Translational control is required for the unfolded protein response and in vivo glucose homeostasis. Mol Cell 7: 1165-1176.

Wilczynska A, Aigueperse C, Kress M, Dautry F, Weil D. 2005. The translational regulator CPEB1 provides a link between dcp1 bodies and stress granules. J Cell Sci 118: 981-992. 

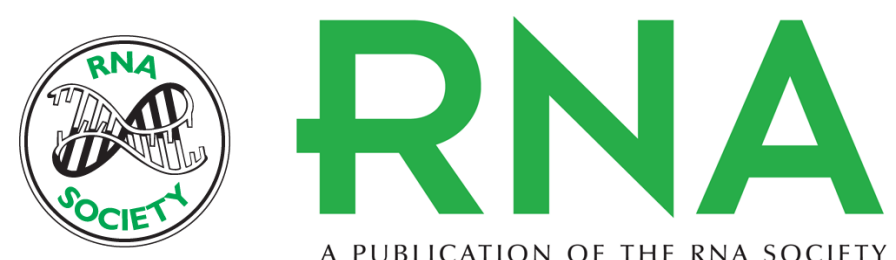

A PUBLICATION OF THE RNA SOCIETY

\section{Metazoan stress granule assembly is mediated by P-elF2 $\alpha$-dependent and -independent mechanisms}

Natalie G. Farny, Nancy L. Kedersha and Pamela A. Silver

RNA 2009 15: 1814-1821 originally published online August 6, 2009

Access the most recent version at doi:10.1261/rna.1684009

Supplemental
Material http://rnajournal.cshlp.org/content/suppl/2009/07/30/rna.1684009.DC1

References This article cites 24 articles, 15 of which can be accessed free at:

http://rnajournal.cshlp.org/content/15/10/1814.full.html\#ref-list-1

\section{License}

Email Alerting Receive free email alerts when new articles cite this article - sign up in the box at the Service top right corner of the article or click here.

To subscribe to RNA go to:

http://rnajournal.cshlp.org/subscriptions 